\title{
Propuesta de una terminología apropiada para las impresiones digitales a partir de la identificación de sus materiales
}

\author{
Iraia Anthonisen-Añabeitia
}

\begin{abstract}
Resumen: La impresión digital en el ámbito artístico no se generaliza hasta finales del siglo XX, por lo que los materiales y las formas de creación pueden considerarse aún jóvenes aunque muy heterogéneas. Uno de los mayores problemas que presenta este tipo de obra es la inexistencia de una terminología precisa. Los procesos se clasifican y nombran de forma muy diversa, revelando una falta de criterios objetivos para su sistematización y generando una falta de comprensión de las técnicas empleadas. Conocer las tecnologías, tipos de tinta, soportes, tipos de acabado y sistemas de montaje ayuda a determinar con mayor precisión las técnicas empleadas, y mediante el uso de herramientas sencillas como lupas o microscopios ópticos es posible averiguar las particularidades que las distinguen. Partiendo de esta información, es posible crear definiciones más claras y concisas, ayudando a establecer las características diferenciadoras de las impresiones digitales y ponerlas en valor como procesos que reflejan la contemporaneidad.
\end{abstract}

Palabras clave: arte contemporáneo, impresión digital, identificación, terminología, conservación, restauración

\section{Proposta de uma terminologia apropriada para as impressões digitais a partir da identificação dos seus materiais}

Resumo: A impressão digital no domínio artístico só se generaliza no final do século XX, pelo que os materiais e as formas de criação podem ser considerados recentes, ainda que muito heterogéneos. Um dos maiores problemas que este tipo de obra apresenta é a inexistência de uma terminologia precisa. Os processos são classificados e nomeados de forma muito diversa, revelando uma falta de critérios objetivos para sua sistematização e gerando uma falta de compreensão das técnicas empregues. Conhecer as tecnologias, tipos de tinta, suportes, tipos de acabamento e sistemas de montagem ajuda a determinar com maior precisão as técnicas utilizadas, e mediante o uso de ferramentas simples como lupas ou microscópios óticos é possível descobrir as particularidades que as distinguem. Com base nesta informação, é possível criar definições mais claras e concisas, ajudando a estabelecer as características diferenciadoras das impressões digitais e a pô-las em valor como processos que refletem a contemporaneidade.

Palavras-chave: arte contemporânea, impressão digital, identificação, terminologia, conservação, restauro

\section{A proposal of an appropriate terminology for digital prints based on the identification of their materials}

Abstract: Digital printing in the arts became widespread by the end of the 20th century, so the materials and forms of creation can still be considered young although very heterogeneous. One of the biggest problems with this type of artworks is the lack of precise terminology. The processes are classified and named in very different ways, revealing a lack of objective criteria for their systematisation and generating a lack of understanding of the techniques used. Understanding the technologies, types of ink, substrates, and types of finishing and mounting systems helps to determine the techniques used with greater precision, and through the use of simple tools such as magnifying glasses or optical microscopes it is possible to find out their distinguishing peculiarities. Based on this information, it is possible to create clearer and more concise definitions, helping to establish the differentiating characteristics of digital prints and to highlight them as processes that reflect contemporaneity.

Keyword: contemporary art, digital print, identification, terminology, conservation, restoration 


\section{Introducción}

La puesta en valor de las obras de arte suele iniciarse por su correcta documentación, derivada de un interés hacia el conocimiento de las particularidades de cada una de ellas, tanto en lo relativo a cuestiones materiales y técnicas como conceptuales, y que pueden ayudar a clasificar y organizar la información para crear un panorama general sobre la época y situación en las que se crearon. En el arte contemporáneo la incorporación de materiales de diversa índole, la aparición y uso de nuevos avances tecnológicos e incluso el uso de no-materiales ha caracterizado momentos históricos, períodos creativos de los artistas, etcétera, por lo que esa necesidad de documentar las obras ha adquirido aún mayor relevancia.

Uno de los desarrollos tecnológicos más importantes que mayores cambios ha suscitado a partir de la segunda mitad del siglo XX, es el uso de las tecnologías digitales. Éstas han ejercido una gran influencia en la sociedad, y como parte de ella, también en la propia creación artística. Además, la gran explosión de lo digital no ocurre hasta prácticamente el cambio de siglo, por tanto, el recorrido artístico de estos materiales y su forma de creación puede considerarse aún joven pero a su vez muy heterogéneo.

Esta situación, ha suscitado entre las y los conservadores de arte una necesidad urgente de entender las tecnologías empleadas y generar nuevos métodos para su conservación, con el fin de intentar evitar las consecuencias de la obsolescencia tecnológica de los software y hardware empleados para la creación de muchas de las obras de arte generadas con estos medios, que impediría su correcta exhibición (García 2010). Sin embargo, las obras artísticas realizadas mediante dispositivos de impresión electrónica, que tienen un resultado material tangible similar al de cualquier fotografía u obra gráfica, parecen haber quedado en tierra de nadie, aunque estos procesos de impresión también evolucionan, al igual que lo hacen los materiales implicados, pero curiosamente la atención hacia estas obras ha pasado bastante desapercibida en pro de otras formas de arte digital, es decir, la materialidad de estas obras y la reflexión hacia ellas parece no haber suscitado demasiado interés.

La variedad de resultados finales de las impresiones digitales permiten su aplicación en distintas disciplinas y desde puntos de vista muy diferentes, sin embargo, como indica Jürgens (2009), su conservación no supone una especialidad en sí misma dentro de la conservación de Bienes Culturales, y básicamente esta función recae en los conservadores de obra sobre papel o fotografía, aunque si se revisan algunas publicaciones relacionadas con estas especialidades, las alusiones a las tecnologías de impresión digital pasan totalmente desapercibidas.

Por otro lado, la idea o creencia preconcebida de que las impresiones digitales pueden considerarse piezas múltiples, y por tanto, carentes de valor como pieza única debido a su supuesta facilidad de reproducción -algo de lo que Benjamin ya hablaba en su conocida obra La obra de arte en la era de la reproducción técnica (Benjamin 2010)-, tampoco ha ayudado a suscitar el interés necesario para la puesta en valor y conservación de estas formas de producción artística tan empleadas entre los artistas contemporáneos. Se podría incluso llegar a decir, que esta cuestión afecta a las impresiones digitales aún en mayor medida que a las técnicas de estampa o la fotografía, que en este sentido parecen haber encontrado cierta credibilidad con el paso de los años. Esta falta de atención a los procesos empleados para la producción de obras generadas por medios de impresión digital se refleja claramente en la falta de especificidad respecto a la terminología empleada para su correcta identificación y catalogación, que deriva en escasos estudios sobre su conservación.

El uso de una terminología apropiada reivindica la especificidad en la forma de crear arte vinculada a un determinado contexto temporal, lo que supone una puesta en valor de los modos de trabajo de un amplio grupo de artistas contemporáneos. Tal y como Herráez (2017) menciona en el Plan Nacional de Conservación Preventiva, la ausencia de la información básica para la identificación y documentación de los bienes culturales está considerada como uno de los indicadores de riesgo para el establecimiento de un plan que asegure la conservación a largo plazo de las piezas artísticas. Por ello resulta imprescindible consensuar una terminología apropiada y un protocolo de identificación entre los diversos entes que conforman el panorama artístico.

\section{_Problemática de los conceptos actuales}

A lo largo de la historia, innumerable cantidad de artistas se han servido de las tecnologías de producción múltiple para llevar a cabo sus creaciones. La xilografía, el aguafuerte - la litografía, han sido y son técnicas de estampación ampliamente utilizadas; pese a que la forma de designar estas obras de arte está muy establecida, la inconsistencia de términos en muchas instituciones sigue siendo un problema, razón por la que han surgido guías para la correcta denominación de este tipo de obras (Ash, Homolka y Lussier 2014). Por otro lado, las técnicas fotomecánicas que consisten en la combinación de fotografía y técnica de estampación- facilitaron la impresión de imágenes fotográficas sobre papel durante los siglos XIX y XX, permitiendo su difusión masiva; estos medios se utilizaron, y actualmente continúan aplicándose, para la realización de grandes tiradas como periódicos, revistas o libros.

Con la irrupción de las tecnologías de impresión digital ya no es necesario el uso de matrices para generar múltiples, la información se almacena electrónicamente a la espera de su impresión cuando ésta sea necesaria, de manera que se pueden realizar trabajos únicos, series limitadas o ilimitadas en función de las necesidades de cada uno de los usuarios. Ya no existe dependencia de una matriz física que se estropea 
con el uso o se destruye al finalizar la tirada, por tanto, se abren nuevas formas de trabajo pero también nuevas interrogantes sobre las obras artísticas generadas con estos medios. Todo este abanico de posibilidades en cuanto a la serialidad de las impresiones, así como la diversificación en cuanto al tipo de trabajos posibles de producir con las tecnologías de impresión digital ha sido revisada con mayor o menor profundidad por varios autores (Insúa 2001; Alcalá y Ariza 2004; Castro 2005; Macías 2015) sobre todo desde el punto de vista de la estampa.

La vertiginosa evolución tecnológica acontecida en los últimos 25 años apenas ha dado tiempo a reflexionar sobre la conservación de las obras impresas mediante tecnologías digitales. Uno de los temas que surge a raíz de esta rápida evolución es la inexistencia de una clara definición en la terminología a emplear; los procesos de impresión se clasifican y nombran de muy diversa forma, o en el peor de los casos, ni siquiera se mencionan, como se puede observar en las cartelas de multitud de obras que forman parte de exposiciones, ferias de arte y catálogos de artistas.

En este sentido, en 2008 el IPI (Image Permanence Institute) llevó a cabo una encuesta en la que se resaltaba que si bien la mayoría delas instituciones participantes poseía impresiones digitales en sus colecciones, sólo unos pocos profesionales se sentían capaces de identificarlas correctamente, y por tanto tampoco disponían de procedimientos claros para cuidar de dichas obras (Burge, Nishimura y Estrada 2008, 2009). En el cuestionario, los autores incluyeron la siguiente definición sobre el término impresión digital: "A digital print is any print (photograph or document) that was created by an electronic printing device where the information regarding dye, ink, or toner placement on the paper originated from a digital file" (Burge, Nishimura y Estrada 2009:6). Pese a que gran parte de los encuestados (75\%) aceptaba esta definición como correcta, en la mayoría de los casos las y los participantes hicieron llegar algunas puntualizaciones que verdaderamente demuestran ciertas discrepancias con la propuesta sugerida, indicando una vez más la falta de consenso real a la hora de establecer una terminología clara.

Al haber transcurrido algunos años desde esta iniciativa del IPI, la definición ha ido modificándose y adaptándose de manera que en la actualidad, en el contexto del proyecto Digital Print Preservation Portal (DP3) (Image Permanence Institute 2007) se presenta una descripción del término diferente, en la que se incluyen no sólo las tecnologías de impresión de no-impacto (aquellas en las que la imagen se forma sin que haya contacto directo con el dispositivo como pueden ser la electrofotografía, inyección de tinta y termografía), sino que contempla otras tecnologías de generación de imágenes como la exposición de papeles de haluros de plata a la luz LED, sin embargo se sigue limitando el uso de los soportes al papel. Estos procesos de exposición de soportes fotosensibles se alejan considerablemente tanto desde el punto de vista material como procesual de las impresiones obtenidas mediante los dispositivos de impresión digital, ya que la imagen no se obtiene mediante gotas de tinta sino por reacciones fotoquímicas del soporte, al igual que en la fotografía tradicional. Por este motivo, numerosas publicaciones engloban éstos últimos procesos dentro de las técnicas fotográficas y no en impresión, entre las que curiosamente se encuentra el portal Graphics Atlas (Image Permanence Institute 2009), también del IPI, que en la categoría de digital únicamente tiene en consideración a la electrofotografía, inyección de tinta y termografía. Estas discrepancias denotan, por tanto, una falta de acuerdo aún a día de hoy, dejando patente que se trata de una cuestión sensible, sobre todo desde el punto de vista de la conservación.

Por otra parte, hoy en día existen nuevas tecnologías y aproximaciones a la impresión digital que requieren de una redefinición del concepto. En general, en las propuestas planteadas sólo se consideran las fotografías o documentos impresos sobre papel, dejando fuera todas aquellas piezas realizadas con clara intención pictórica, escultórica o instalaciones, y excluyendo otros soportes que no sean papel, cuando gracias a la tecnología de inyección con tintas de curado ultravioleta o a la sublimación, han surgido otras muchas opciones. Tampoco tiene en consideración los materiales que por diversos motivos se añaden en el proceso de postimpresión y que pasan a formar un todo con la impresión. Por este motivo, la definición renovada para un contexto artístico podría ser algo así como:

Una impresión digital es cualquier objeto impreso por un dispositivo de impresión electrónico a partir de un archivo digital que indica la ubicación de la tinta o tóner sobre un soporte rígido o flexible, y que puede llevar o no otra serie de materiales añadidos tanto en su superficie como en su reverso para otorgar acabados especiales a la impresión.

Pese a que en la actualidad el término impresión digital se ha convertido en un estándar de facto para designar aquellas obras impresas mediante tecnologías electrónicas, siendo el motivo por el que se emplea en este trabajo, el término deriva de la traducción literal del inglés digital print, donde print se utiliza para denominar diferentes tipos de producción artística como las originadas por las técnicas de estampación, fotografía o impresión digital, print, photographic print, digital print. En función del área de conocimiento desde el que se aborda el estudio de las impresiones digitales se han empleado también otras formas para designarlas, aunque hoy en día hayan quedado en desuso; desde el punto de vista de la fotografía el término empleado en las publicaciones de algunos autores de relevancia como Lavédrine, Monod y Gandolfo (2003) sería computer output print, mientras que desde el ámbito de la estampa se proponía computer printmaking (Noble 1997) e incluso Jürgens (1999) hablaba sobre hard copy.

Para algunos conservadores el término impresión digital utilizado para las obras generadas con dispositivos electrónicos sigue sin ser del todo definitorio ya que el término "digital" muestra dos acepciones que nada tienen que ver con el tema a tratar: por un lado se define como algo 
que hace referencia a los dedos, y por otro a los números (dígitos). Acorde a la segunda acepción, la forma de procesar la información en un ordenador se basa en un sistema binario de 0 y 1 , pero realmente la electrónica es la que genera las imágenes y textos, razón por la que hay quienes defienden que en el lenguaje técnico a emplear entre profesionales del ámbito artístico, sería conveniente hablar de impresión electrónica o imagen electrónica. Al igual que cuando se habla de obras pictóricas, escultóricas o de dibujo se trata de concretar la técnica específica empleada como óleo sobre lienzo, hierro, o grafito sobre papel, se debería aspirar a establecer esos mismos niveles de precisión en la identificación de las impresiones digitales, tal y como ya se apuntaba en las I Jornadas de Conservación de Patrimonio Fotográfico celebradas en Madrid (Maynés 2012).

A esto se suma la reticencia que muchos artistas, galeristas y demás profesionales del arte muestran a la hora de aceptar y emplear el término de impresión digital debido al uso extendido que se hace de él en cualquier ámbito de la vida cotidiana, así como por las connotaciones negativas que ha tenido a lo largo de la historia. Por este motivo se han ideado una serie de términos y neologismos para distinguir las impresiones de uso cotidiano carentes de valor artístico de aquellas que sí lo tienen, o quizá también para no mostrar tan abiertamente el origen de las obras generadas mediante dispositivos electrónicos.

Debido a que las primeras formulaciones de tinta para producir impresiones digitales se basaban en tintes y no ofrecían buenos resultados en cuanto a su estabilidad y permanencia (Wilhelm 2006), el intento de ocultar el proceso de creación se hizo algo habitual para evitar reticencias en la compra de obras de arte producidas mediante estos dispositivos. A comienzos de la década de los 90, Jack Duganne de Nash Editions acuña el término giclée -del francés gicler- para designar obras impresas mediante las impresoras IRIS de inyección de tinta y diferenciarlas de las impresiones sin ninguna finalidad artística (Johnson 2005). Este término que pretendía ser sinónimo de calidad ha llegado hasta nuestros días, sin embargo, su concepto inicial se fue desdibujando hasta el punto que hoy día se emplea para designar cualquier tipo de imagen impresa con inyección de tinta, sea ésta una obra original o una reproducción, que supuestamente cumple con unos requisitos de calidad pero que no define ni el proceso ni los materiales empleados.

Otro de los conceptos ampliamente utilizados para designar las impresiones digitales en un intento de avalar su calidad y ofrecer cierta garantía sobre su permanencia en el tiempo es la inclusión del término "archivo" o archival (en inglés) en la información sobre la técnica de impresión, como archival pigment print o archival print. Este término se emplea para designar los soportes de papel libres de ácido realizados a base de fibras de algodón por ser conocidos por su mayor estabilidad ante los agentes de deterioro en comparación con otros tipos de papel. Sin embargo, es muy difícil encontrar información precisa sobre las características de los soportes de papel comercializados para la impresión digital. Además, la estabilidad de las impresiones también depende de otros factores como son el tipo de tintas utilizadas, de si llevan o no otros materiales añadidos, del sistema de almacenaje utilizado y el tipo de montaje empleado para su exhibición, así como toda una serie de condiciones ambientales que rodean a la obra, por tanto, desde hace algunos años el término "archivo" no es recomendable para designar este tipo de obras (Sheppard 2005), aunque es posible seguir encontrándose en algunos casos ya que varios laboratorios de impresión continúan empleando este concepto como signo de calidad.

A este tipo de términos cabe añadir los sellos de calidad que algunas empresas ofrecen, como es el caso de Digigraphie ${ }^{\circledR}$ de Epson. Este sello, que existe desde el 2003, sólo lo pueden adquirir los laboratorios de impresión y artistas que se comprometen a trabajar con una serie concreta de impresoras y tintas de Epson, así como unos soportes específicos de la propia Epson, Hahnemühle o Canson ${ }^{\circledR}$, para garantizar la calidad y estabilidad de las impresiones (Epson Europe 2020). En este sentido, cabe destacar que el nombre de estos sellos de calidad tampoco resulta lo suficientementeclaro o descriptivo desde el punto de vista de la conservación, ya que al igual que ha ocurrido en el pasado con otras marcas comerciales, éstas pueden desaparecer, y al cabo de los años puede resultar muy difícil comprender el significado de estas marcas o las características de este tipo de impresiones. Lo mismo ocurre con los nombres comerciales que han pasado a describir formas concretas de presentar y exhibir las imágenes impresas, como es el caso de Diasec $^{\circledast}$; realmente se trata de una marca registrada que describe un proceso que se empleaba básicamente para los montajes de procesos fotográficos de revelado digital, pero que hoy día se utilizan también para la impresión digital, por lo que no determina el tipo de tecnología empleada para la impresión, ni las tintas, ni el tipo de soporte empleado.

Por último, cabe destacar, que además de todas estas variables, existen otras confusiones terminológicas derivadas del tipo de imagen producida mediante la impresión digital, es decir, en ocasiones los objetos se clasifican por lo que parecen y no por lo que realmente son [figura 1]. Esto ocurre asiduamente con las obras de carácter fotográfico; la imagen conceptualmente puede ser una fotografía, pero el proceso de obtención de la misma puede no ser fotográfico, y en vez de emplear materiales fotosensibles y reactivos, lo que genera la imagen es un dispositivo electrónico a través de gotas de tinta. En el libro de Lavédrine, Monod y Gandolfo (2003) esta diferenciación se indica claramente ya que las impresiones digitales se presentan como una categoría fuera de la fotografía, lo que indica que si bien este tipo de impresiones pueden tener un trasfondo conceptual en lo fotográfico, materialmente nada tienen que ver. Esta diferenciación curiosamente no ocurre tan a menudo con otras aproximaciones a la impresión digital como la estampa o pintura, pero lo que sí recalca una vez más, es la necesidad de establecer claramente la materialidad de las obras impresas con tecnología digital en 
pro de su conservación. A todo esto cabe añadir el concepto técnica mixta, tan difundido para designar todo tipo de obras que aúnan varias técnicas y que también afecta a las impresiones digitales que se combinan con técnicas como por ejemplo la pintura, dibujo o estampa, aumentando aún más la confusión existente.

Teniendo en cuenta todo lo anterior, es posible realizar una categorización de la variedad terminológica empleada para clasificar y denominar las impresiones digitales con independencia de los materiales constituyentes de las obras. Estas variables se agrupan en cuatro apartados:

\section{Conceptos generalistas; impresión, impresión digital}

2. Nombres comerciales; Diasec, Digigraphie, Ultrachrome

3. Términos confusos; giclée, archival print, archival pigment print

4. Términos incorrectos; fotografía, tinta sobre papel, pigmento sobre papel, pigment print

Como se ha mencionado con anterioridad, ninguna de estas fórmulas describe claramente el objeto artístico, ya que no indican ni la técnica ni los materiales empleados. Esto no sólo denota una falta de criterios objetivos para la sistematización de la identificación, sino que genera una falta de comprensión y confusión sobre las técnicas empleadas, que posiblemente tiene su reflejo en la conservación de este tipo de obras de arte.

\section{Pautas para la identificación}

Una de las principales dificultades para la identificación y empleo de una correcta terminología radica en la evolución y uso de las tecnologías, las tintas y los soportes. Conocer el orden cronológico en el que aparecieron y saber cuándo se emplearon más habitualmente puede ayudar a determinar con mayor precisión las técnicas empleadas en cada obra de arte; algunos sistemas como el láser se desarrollaron antes de que su uso se extendiera al mundo digital, por lo que el resultado de la obra impresa por uno u otro sistema apenas podrá distinguirse si no se conocen más datos sobre la obra, como por ejemplo la fecha de creación. La inyección de tinta y la sublimación son tecnologías algo más nuevas, sin embargo las tintas y soportes empleados han ido evolucionando a lo largo del tiempo [figura 2].

Con el fin de subsanar los problemas ocasionados por la disparidad de términos empleados a lo largo de los años en el ámbito de la creación artística para designar las obras impresas con tecnología de impresión digital, han aparecido algunas sugerencias y propuestas que implican

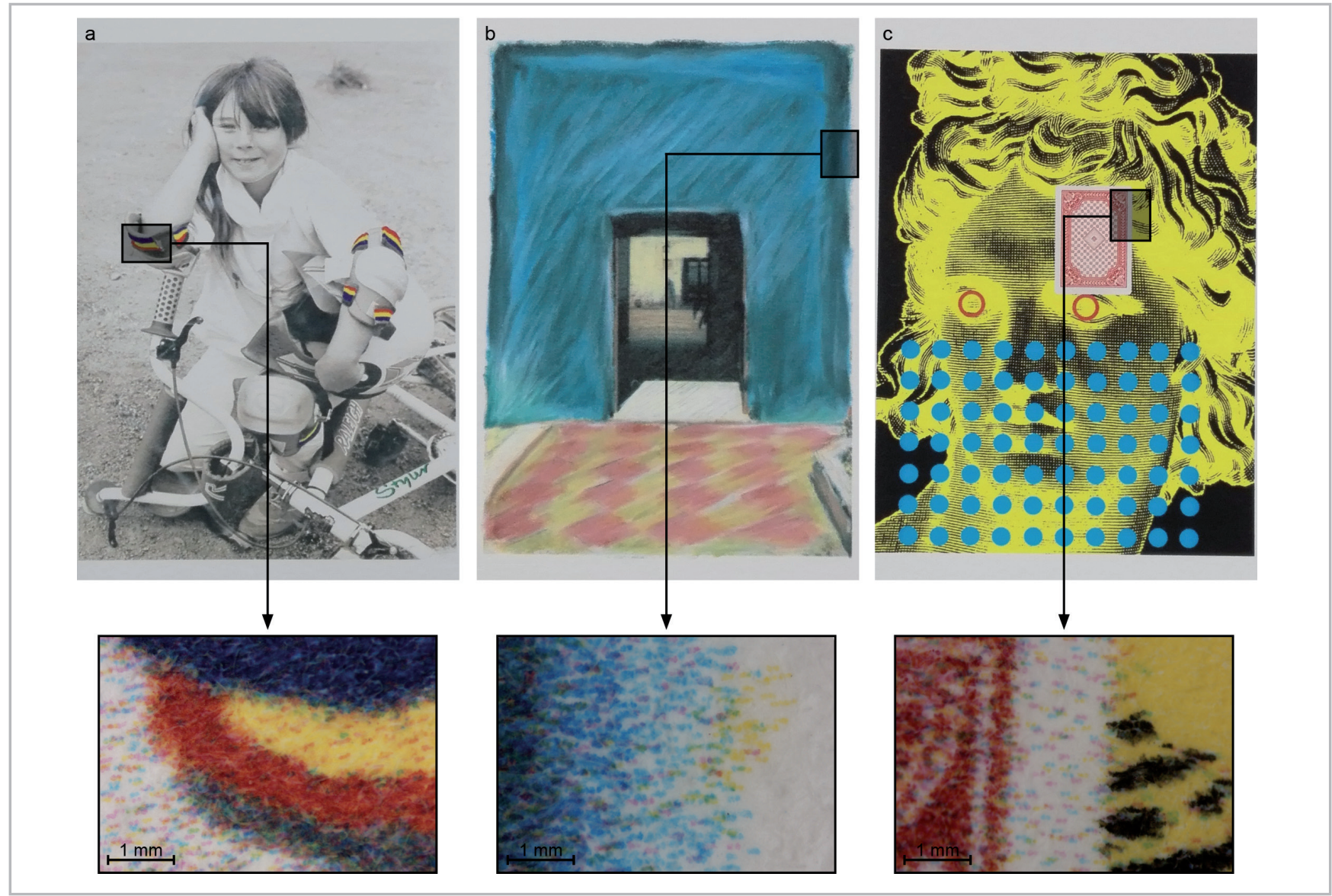

Figura 1.- Ejemplos tomados del International Digital Miniature Print Portfolio de 2002 (CFPR): a) imagen fotográfica, b) dibujo a pastel, y c) serigrafía. Como se aprecia en las ventanas de detalle, todas las imágenes se han producido con tecnología de inyección de tinta, haciendo constar una vez más la importancia en la correcta identificación de este tipo de obras 


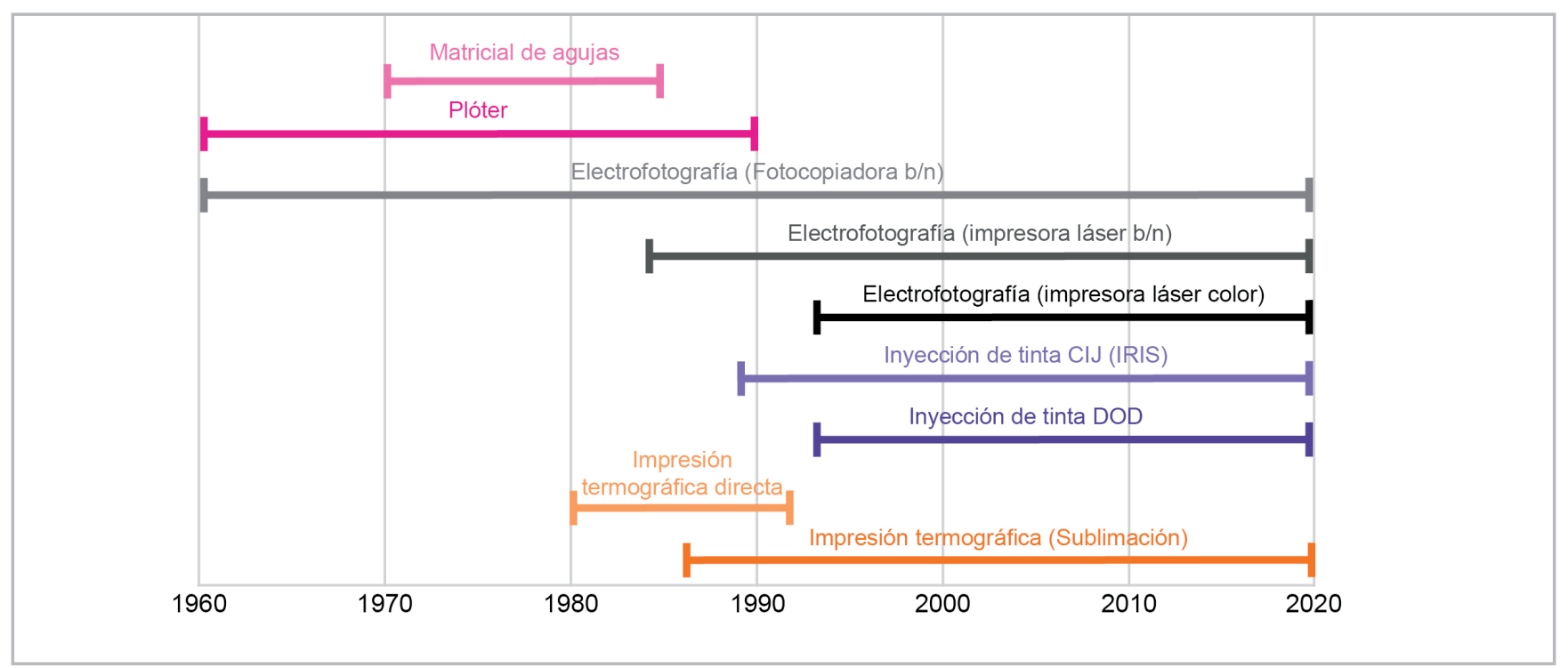

Figura 2.- Línea del tiempo que resume los períodos de utilización de las diversas tecnologías de impresión digital para la generación de obras de arte. Los tramos indicados en cada caso abarcan la tecnología en general, sin embargo hay que tener en cuenta la evolución de algunas de ellas, que ha conllevado ciertas variables en el proceso y en los materiales empleados

la recolección de información sobre dichas impresiones. Jürgens (2009) es uno de los primeros en atender a estas cuestiones en su conocido libro The Digital Print. A complete Guide to processes, Identification and Preservation, donde incluye una propuesta de ficha técnica a cumplimentar cuando se produce la obra o entra a formar parte de alguna colección. Ese mismo año el American Institute for Conservation (AIC) desarrolla el Photographic Information Record (American Institute for Conservation 2009) para recopilar datos sobre las obras impresas mediante una serie de preguntas diseñadas a modo de cuestionario que se ha traducido a varios idiomas con la intención de convertirse en un formulario estándar a nivel internacional. Sin embargo, en ocasiones es habitual enfrentarse a situaciones en las que la recopilación de la información es compleja; hay artistas que transfieren la impresión de sus trabajos a laboratorios especializados y en ocasiones se produce una pérdida de control en cuanto a la producción. Puede que el o la artista desconozca el nombre de los materiales empleados, y a menudo la información facilitada por el laboratorio de impresión sea más acorde a los términos empleados en su jerga o a los nombres comerciales de los materiales utilizados.

Por este motivo, la forma más sencilla de evitar confusiones terminológicas consiste en la correcta identificación de las impresiones por parte de las y los conservadores cuando la obra pasa a formar parte de una colección. El primer paso se fundamenta en intentar averiguar los materiales que las componen mediante el análisis organoléptico, que no precisa de toma de muestras, con la ayuda de lupas o microscopios en caso de que fuera necesario. Con este tipo de herramientas de magnificación es posible realizar un análisis más exhaustivo de las características observadas a simple vista, de manera que permitan ratificar algunas cuestiones como son: si la textura del soporte queda visible u oculta bajo un recubrimiento, dónde se deposita la tinta
[Figura 3]-sobre el soporte o en el soporte-y la forma en que lo hace, pero también si se han aplicado capas protectoras a la superficie. Todo ello puede detectarse mediante el uso de polarizadores incorporados al microscopio o lupa, lo que permite acertar con mayor precisión sobre las características principales de aquellas impresiones que en principio puedan generar dudas.

Este proceso, que requiere un previo conocimiento de aspectos teóricos básicos, se puede dividir en tres fases principales:

1.Elanálisis delas características superficiales de la impresión. Mediante el empleo de diversas fuentes de iluminación y su orientación en diversos ángulos se pueden determinar características relativas a la textura de la superficie impresa, su relieve, la uniformidad del brillo superficial y la calidad y definición de la imagen.

Las impresiones electrofotográficas se caracterizan por un sutil brillo diferencial entre las zonas impresas y sin imprimir debido a la composición del tóner -resinas termoplásticas-; también suelen mostrar una trama regular característica en comparación con otras tecnologías, un punteado en zonas no impresas causado por restos de tóner que no se fijan debidamente en el proceso de impresión y que manchan la superficie, así como por una serie de marcas de seguridad que son distintivas de cada modelo de impresora [figura $4 \mathrm{a}, \mathrm{b}$ y c]. Por otro lado, las impresiones termográficas de sublimación muestran una gran calidad con transiciones de color suaves debido a la composición de las tintas; en este caso, la apariencia puede variar en función del soporte empleado para la impresión, que pueden ser desde textiles a soportes rígidos de diversa naturaleza, que pueden mostrar su apariencia natural o llevar recubrimientos de color blanco para evitar interferencias con las imagen impresa [figura $4 \mathrm{~d}$, eyf]. 


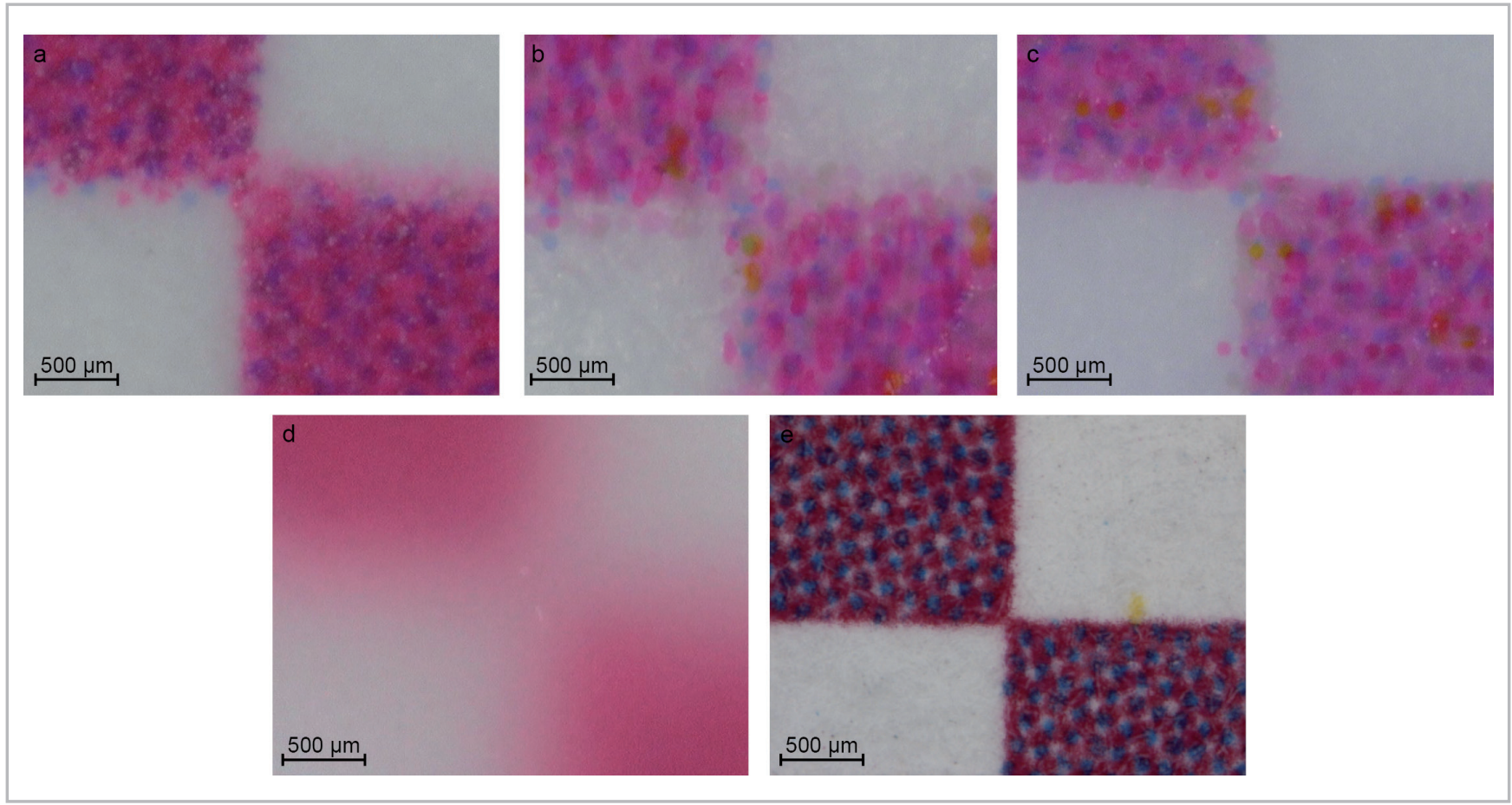

Figura 3.-. Imágenes de magnificación obtenidas con microscopio digital Dino-Lite model AM4113 ZT(R4) que muestran de manera generalizada el lugar en el que se depositan las tintas y la forma en que lo hacen en función de las tecnologías de impresión digital: a) Inyección de tinta sobre papel artístico mate; b) Inyección de tinta sobre papel baritado; c) Inyección de tinta sobre papel RC; d) Sublimación de tintes sobre aluminio con acabado de color blanco; e) Electrofotografía de tóner seco sobre papel común. Mientras a, b, c y d quedan más o menos inmersas en las IRL, la muestra d se percibe con total nitidez, indicando que las tintas quedan depositadas en la superficie del soporte

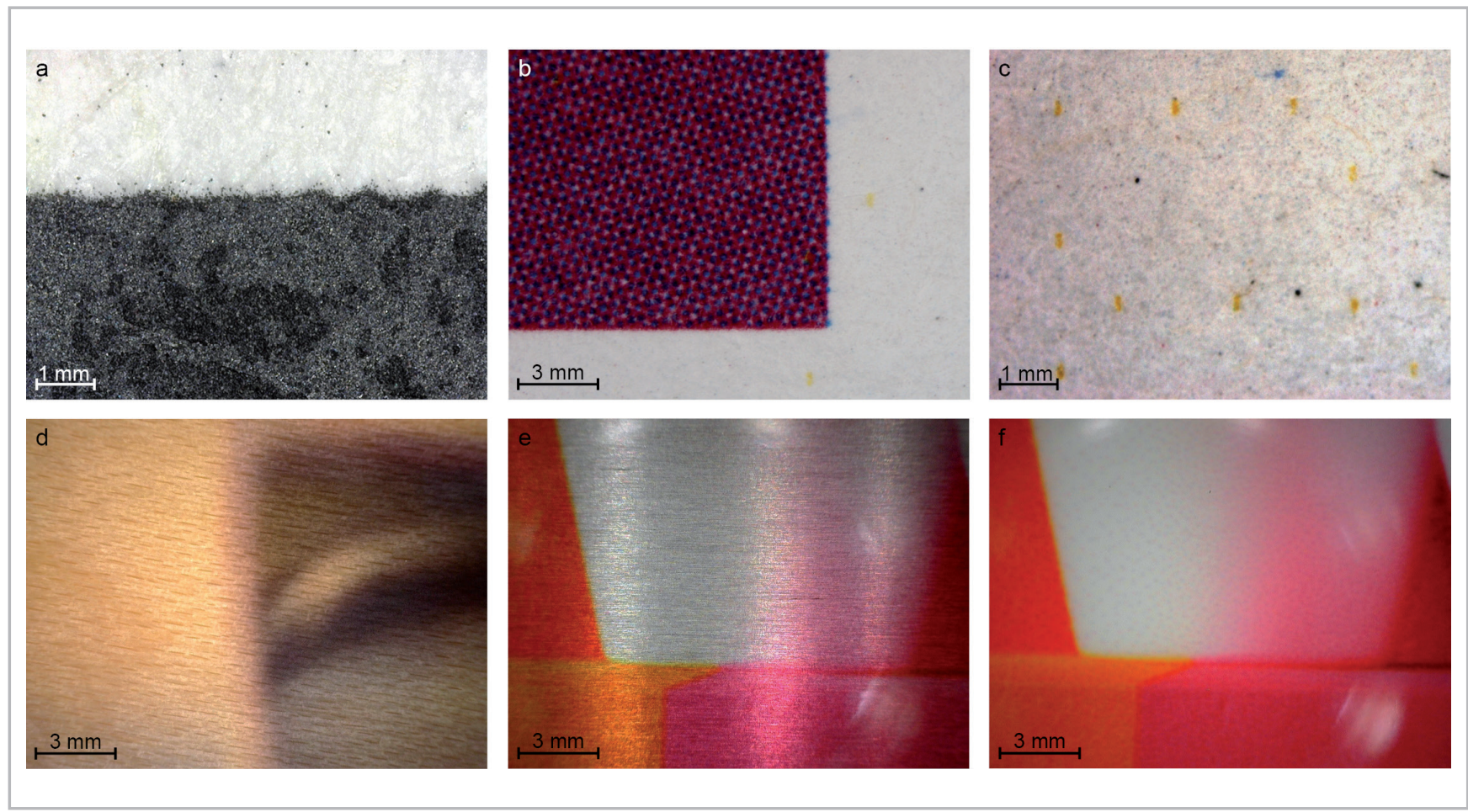

Figura 4.- Características distintivas de las impresiones electrofotográficas: a) Brillo diferencial causado entre las zonas impresas y sin imprimir; b) Trama característica; c) Marcas de seguridad distintivas (color amarillo) y punteado causado por restos de tóner; y características distintivas de las impresiones termográficas de sublimación: d) Impresión realizada sobre madera de arce; e) Impresión realizada sobre soporte de aluminio; f) Impresión realizada sobre soporte de aluminio con recubrimiento blanco 

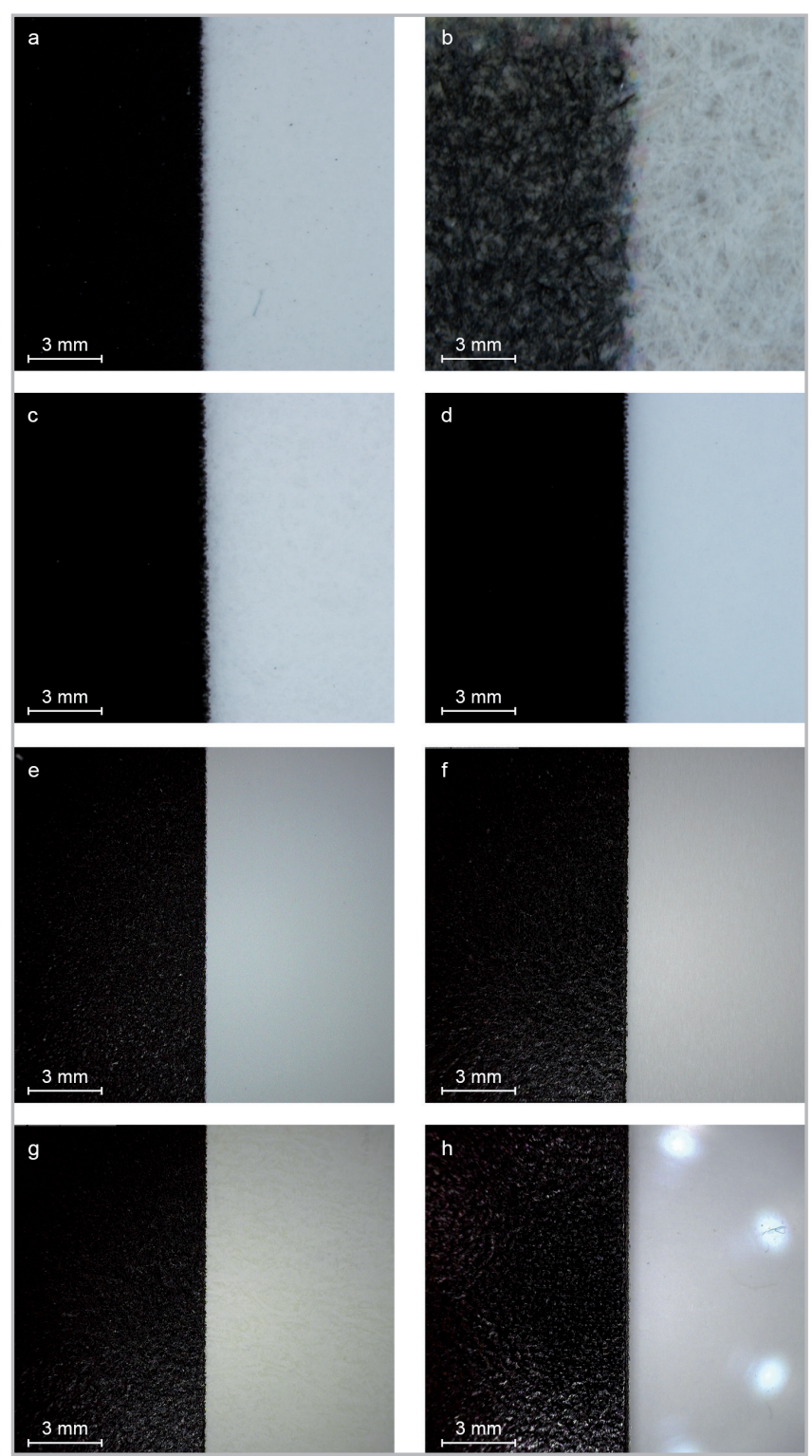

Figura 5.- Aspecto de varios soportes para impresión por inyección de tinta bajo magnificación al microscopio. La mancha negra a la izquierda muestra la zona impresa, la zona blanca se trata de la zona no impresa del soporte: a) Papel de tipo artístico; b) Papel japonés; c) Papel baritado; d) Papel RC; e) Dibond;f) PVC; g) Cartón pluma; h) PMMA.

En cuanto a la inyección de tinta, el tipo de tintas y los soportes son más variados, por tanto, el resultado final de la impresión también se verá diferente. Los soportes de papel tipo artístico se caracterizan por superficies mate, con tonos que oscilan del blanco al beige, con mayor o menor textura y aspecto aterciopelado, por el contrario, los papeles RC tienen una superficie blanca lisa de aspecto plástico. Estas características de los soportes de papel afectan al aspecto que muestran las tintas de base acuosa, que varía considerablemente en cuanto a su densidad de color y en la definición de los bordes entre las zonas impresas y sin imprimir [figura 5 a, b, c y d]; en función de la apariencia de las tintas también se puede estimar si la impresión ha sido producida con tintes o pigmentos [figura 6]. El tipo de tintas empleadas también afecta considerablemente al resultado final, de manera que, mediante el uso de tintas de curado ultravioleta, se pueden observar diferencias de brillo entre las zonas impresas y las que no lo están, así como cierto relieve creado por la tinta sobre la superficie, que difiere notablemente de las tintas de base acuosa [figura 5 e, f, g y h]. Además de estas diferencias detectables con herramientas de magnificación, también es posible especular sobre el tipo de tintas empleado analizando la obra más a grosso modo, de manera que, si sólo se observa un único soporte rígido y la obra de arte ha sido creada a partir del año 2000, posiblemente la pieza haya sido impresa mediante tecnología de inyección de tinta con tintas UV; si su fecha es anterior, seguramente haya sido impresa con tintas de tipo solvente.

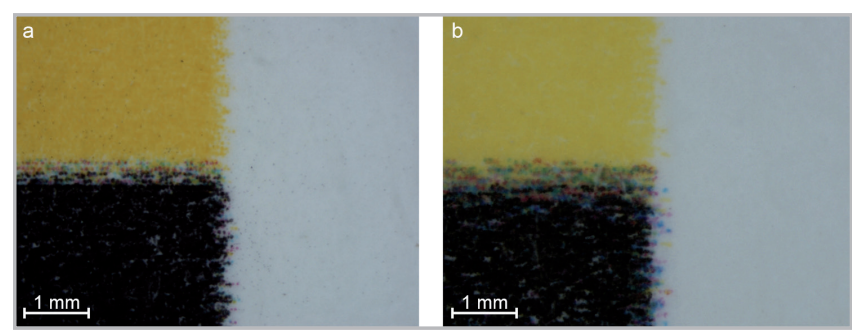

Figura 6.- Diferencias entre tintas de base acuosa basadas en pigmentos (a) o tintes (b). Se percibe una clara diferencia en la intensidad del color y definición del punto debido a la mayor penetración de los tintes en el soporte tanto en sentido vertical como horizontal

En ocasiones es posible encontrar impresiones con acabados especiales que modifican de alguna manera su aspecto general, mostrando un acabado uniforme independientemente de la combinación tinta/soporte empleado, por lo que habrá que recurrir a otras formas de observar la impresión para tratar de averiguar los materiales que la componen, como por ejemplo la observación de su perímetro y/o reverso. Estas modificaciones, que también pueden detectarse con facilidad mediante la magnificación, pueden consistir entre otros, en la aplicación de films plásticos en los soportes de papel, como son los laminados [figura 7 a y b] y la aplicación de capas de brillo mediante las impresoras diseñadas para las tintas de curado ultravioleta, que pueden variar en su grosor y textura [figura 7 c y d].

2. La observación del canto de las piezas sirve de complemento a la anterior inspección ya que permite detectar si la impresión está compuesta por una capa (soporte impreso), por dos (soporte impreso y montaje), tres (impresión, montaje y acabado) o más capas, confirmando o desechando algunas sospechas ya anotadas en la fase anterior [figura 8].

Prestar atención al perímetro de las impresiones, y especialmente a las esquinas, también puede resultar de interés, debido a que éstas suelen ser una de las zonas 


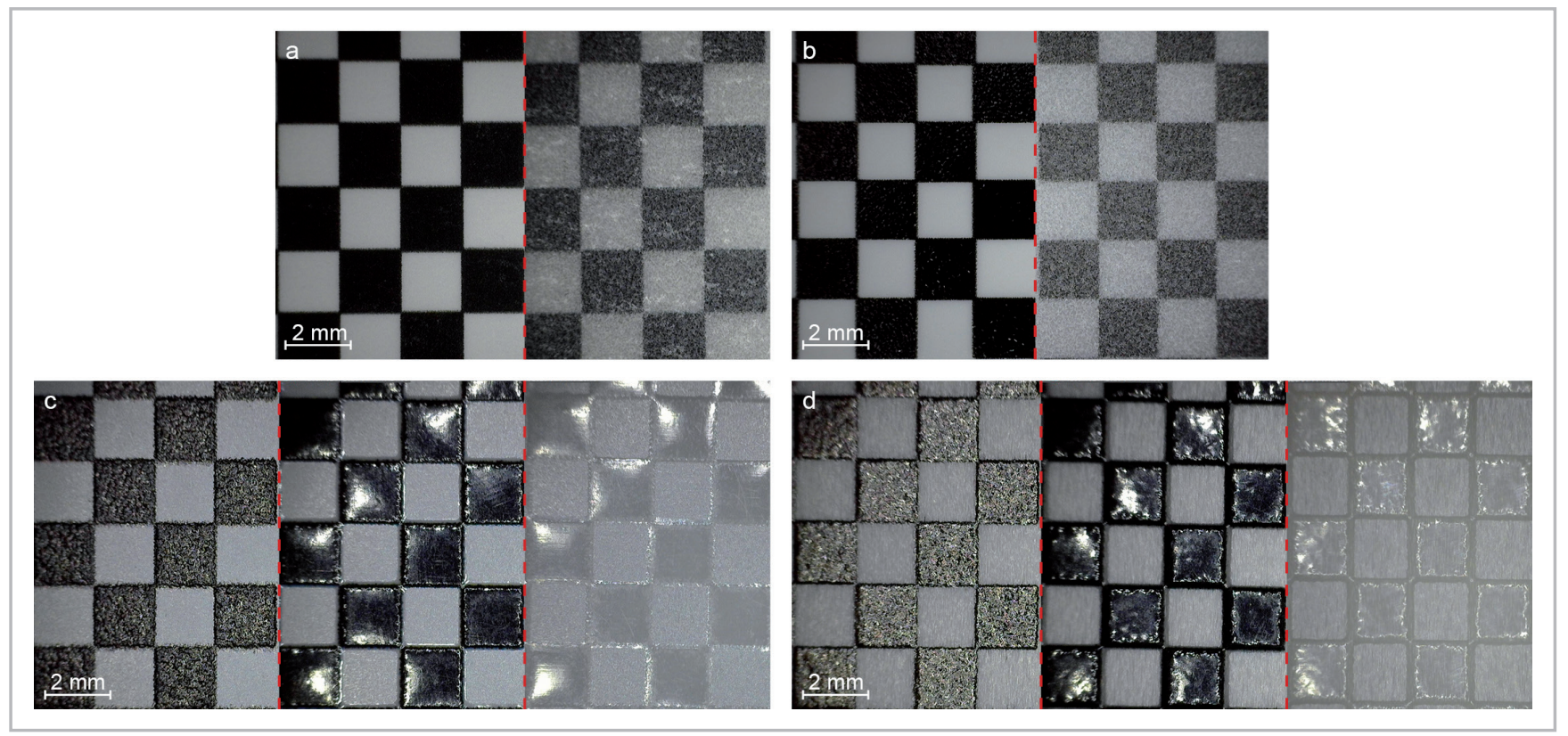

Figura 7.- Algunos acabados especiales aplicados a las impresiones digitales: a) Papel de tipo artístico sin laminar (izquierda) y laminado PSA mate (derecha); b) Papel RC sin laminar (izquierda) y laminado PSA mate (derecha); c) Dibond impreso con tintas curables en ultravioleta (izquierda), tinta y una capa impresa de barniz brillo (centro) e impresión de una capa de barniz brillo directamente sobre el soporte (derecha); d) PVC impreso con tintas curable en ultravioleta (izquierda), tinta más cinco capas de barniz brillo impresas (centro) e impresión de cinco capas de barniz brillo directamente sobre el soporte.
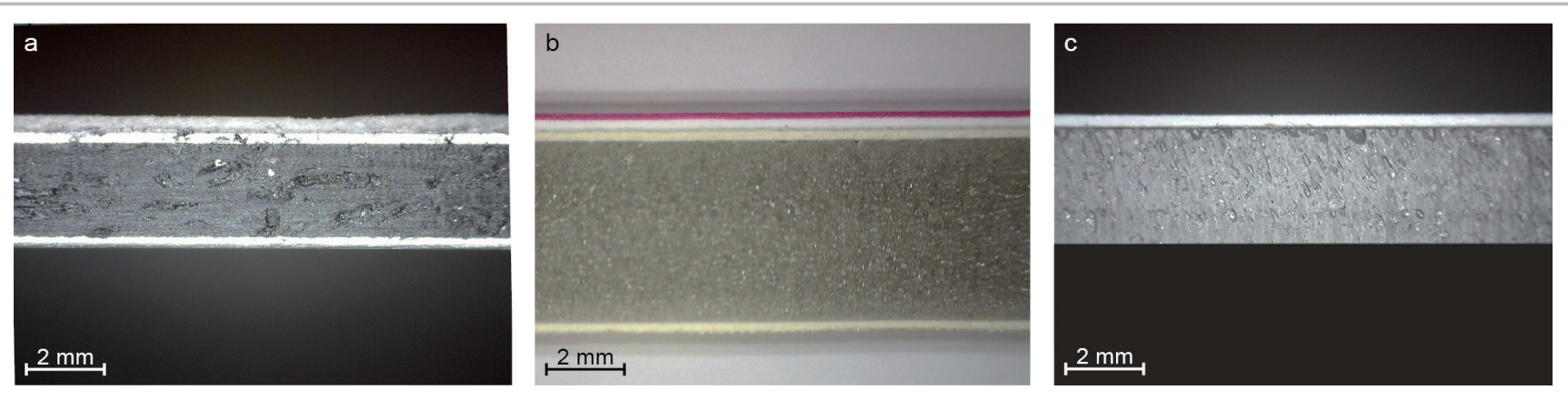

Figura 8.- Corte transversal de impresiones realizadas en papel artístico montadas sobre diversos soportes mediante adhesivos PSA: a) Dibond ${ }^{\oplus}$; b) Cartón pluma; c) PMMA.

más susceptibles de sufrir deterioros, dejando a la vista los diferentes materiales que pueden componer las impresiones, o incluso su proceso de impresión [figura 9]. En este punto puede resultar interesante la ayuda de un microscopio o lupa para la detección de los diferentes materiales con mayor detalle.

3. En el caso de proseguir con dudas respecto a la identificación, es recomendable tratar de comparar los datos y las imágenes tomadas con la información ofrecida en las principales fuentes como el DP3 o Graphics Atlas. También existe un banco de imágenes online creado por Jürgens (2019) donde se puede observar infinidad de muestras impresas mediante una gran cantidad de variables tecnológicas sobre diferentes materiales y tipos de tinta que ayudan a identificar con mayor certeza las impresiones.

\section{Propuesta de una nueva terminología}

Con la información obtenida, se puede desarrollar un esquema de los materiales constituyentes de cada obra, que servirá para conocer su proceso de producción y también para denominarlo de acuerdo a una nomenclatura precisa y exenta de nombres comerciales.

Como se ha mencionado con anterioridad, a la hora de conservar impresiones digitales resulta esencial conocer los diversos tipos de tecnología existentes, sus características y el tipo de tintas y soportes disponibles en cada caso para así poder crear definiciones más claras y concisas, y establecer las características diferenciadoras. Esta precisión, obviamente, debe tener su reflejo en la catalogación de las obras, que a su vez determina la información de las cartelas que aparecen 
Tabla 1.- Esquema de la información sobre los materiales de una impresión digital (de general a precisa)

\begin{tabular}{|c|c|c|c|c|}
\hline Nombre genérico & $\begin{array}{c}\text { Tecnología de impresión } \\
\text { (proceso) }\end{array}$ & Soporte & Acabado & Tipo de montaje \\
\hline \multirow{5}{*}{ Impresión digital } & \multirow{5}{*}{$\begin{array}{c}\text { Inyección de tinta } \\
\text { Sublimación de tintes } \\
\text { Electrofotografía }\end{array}$} & $\begin{array}{l}\text { Papel: } \\
\text { - Artístico } \\
\text { - Microporoso } \\
\text { - Polimérico } \\
\text { - RC }\end{array}$ & \multirow{5}{*}{$\begin{array}{l}\text { Laminado } \\
\text { Barnizado } \\
\text { Pintado } \\
\text { Cortado }\end{array}$} & \multirow{5}{*}{$\begin{array}{l}\text { Encapsulado } \\
\text { Enmarcado }\end{array}$} \\
\hline & & $\begin{array}{l}\text { Textil: } \\
\text { - Lienzo } \\
\text { - Seda } \\
\text { - Poliéster }\end{array}$ & & \\
\hline & & $\begin{array}{l}\text { Plástico: } \\
\text { - PMMA } \\
\text { - PVC }\end{array}$ & & \\
\hline & & $\begin{array}{l}\text { Metal: } \\
\text { - Aluminio }\end{array}$ & & \\
\hline & & $\begin{array}{l}\text { Materiales compuestos: } \\
\text { - Cartón pluma } \\
\text { - Paneles de aluminio } \\
\text { compuesto }\end{array}$ & & \\
\hline
\end{tabular}

en las exhibiciones junto con las obras, y que ayudará al visitante a comprender la riqueza existente en el ámbito de la impresión digital, generando una vez más información importante para su puesta en valor.

Aunque al personal encargado de la conservación de las obras le interese obtener todos los datos posibles sobre una determinada pieza, la información que acompaña a las impresiones digitales en una exposición no tiene por qué ser tan extensa, por no resultar de relevancia para la gran mayoría del público. Por este motivo, y cumpliendo con la función didáctica de museos e instituciones, sería suficiente con que tal y como se muestra en la siguiente [tabla 1], la información básica se redujera a los dos primeros términos (nombre genérico y tecnología de impresión), pudiendo ser ampliada en función de las necesidades para ofrecer datos más específicos.

\section{Conclusiones}

La conservación de las obras artísticas comienza por un buen conocimiento de las técnicas y materiales empleados para su creación. En el caso de las obras creadas mediante dispositivos de impresión digital, esta cuestión también resulta esencial, por un lado, debido a la evolución tecnológica que ha acarreado cambios en los procesos y materiales para la obtención de imágenes, y por otro lado, por las posibilidades que existen de combinar materiales, acabados y sistemas de montaje, dando lugar a una gran variedad de resultados.

Cada tecnología de impresión permite el uso de unos materiales determinados, siendo la inyección de tinta la más versátil y empleada en la actualidad.

Mediante el examen organoléptico basado en las tres fases descritas es posible acotar con mayor certeza la materialidad de las impresiones digitales, permitiendo denominar a los objetos por lo que son y no por su aspecto, lo que facilita la correcta toma de decisiones respecto a la conservación de las impresiones digitales, además de poner en conocimiento los procesos específicos que forman parte de un número cada vez mayor de obras artísticas del patrimonio contemporáneo.

\section{Referencias}

ALCALÁ, J R. y ARIZA, J. (Coord.). (2004). Explorando el laberinto. Creación e investigación en torno a la gráfica digital a comienzos del siglo 21. Cuenca: Servicio de Publicaciones de la Universidad de Castilla-La Mancha.

AMERICAN INSTITUTE FOR CONSERVATION (2009). “Photographic Information Record". https://www.culturalheritage.org/ membership/groups-and-networks/photographic-materialsgroup/publications/photographic-information-record [consulta $: 1 / 9 / 2020]$. 
ASH, N.; HOMOLKA, S. y LUSSIER, S. (2014). Descriptive Terminology for Works of Art on Paper. Guidelines for the accurate and consistent description of the materials and techniques of drawings, prints and collages. Filadelfia: Philadelphia Museum of Art.

BENJAMIN, W. (2010). La obra de arte en la época de su reproducción mecánica. Madrid: Casimiro.

BURGE, D.; NISHIMURA, D. y ESTRADA, M. (2008). "Summary of the DP3 Project Survey of Digital Print Experience within Libraries, Archives, and Museums". En Archiving Conference, Berna: Society for Imaging Science and Technology, 133-136.

BURGE, D., NISHIMURA, D. y ESTRADA, M. (2009). "What do you mean when you say digital print?", Archival Outlook, March/ April: 6-25.

CASTRO, K. (2005). Mapas invisibles para una gráfica electrónica: de la huella incisa al grabado con luz. Vigo: Universidade de Vigo.

EPSON EUROPE (2020). “Digigraphie by Epson". https://www. digigraphie.com/en/index.htm [consulta: 4/10/2020].

GARCÍA, L. (2010). Conservación y Restauración de Arte Digital (Tesis Doctoral). Madrid: Universidad Europea de Madrid.

HERRÁEZ, J. A. (2017). Fundamentos de Conservación Preventiva. Madrid: Instituto del Patrimonio Cultural de España (IPCE).

IMAGE PERMANENCE INSTITUTE [IPI] (2007). "Digital Print Preservation Portal (DP3)". http://www.dp3project.org/ [consulta: 15/10/2020].

IMAGE PERMANENCE INSTITUTE [IPI] (2009). "Graphics Atlas". http://www.graphicsatlas.org/[consulta: 11/10/2020].

INSÚA, L. (2003). La estampa digital. El grabado generado por ordenador (Tesis doctoral). Madrid: Universidad Complutense de Madrid.

JOHNSON, H. (2005). Mastering Digital Printing (2a ed.). Boston: Thomson Course Technology.

JÜRGENS, M. (1999). Preservation of Ink Jet Hardcopies. Capstone Project, Cross-Disciplinary Studies. Rochester: Rochester Institute of Technology.

JÜRGENS, M.C. (2009). The digital print. Identification and Preservation. Los Angeles: The Getty Conservation Institute.

JÜRGENS, M. (2019). "The Eye". http://the-eye.nl/ [consulta: 5/10/2020].

LAVÉDRINE, B; MONOD, S. y GANDOLFO, J.P. (2003). A Guide to Preventive Conservation of Photograph Collections. Los Angeles: Getty Conservation Institute.

MACÍAS, J. M. (2015). Arte gráfico digital. Propuestas para una creación mediante procesos híbridos (Tesis doctoral). Málaga: Universidad de Málaga.
MAYNÉS, P. (2012). “Terminología para los sistemas de producción de imagen múltiple". En I Jornadas sobre Conservación Preventiva de Fotografía Contemporánea y Soportes Electrónicos, Madrid.

NOBLE, J. (1997). "Fractal attraction: Print meets computer". En Computers and art, Mealing, S. (ed.). Exeter: Intellect Books, 77-95.

SHEPPARD, R. (2005). "What does archival really mean?", Digital PhotoPro, 3 (3): 130.

WILHELM, H. (2006) "A 15-year history of digital printing technology and print permanence in the evolution of digital fine art photography - From 1991 to 2006". En NIP22 \& Digital Fabrication Conference. International Conference on Digital Printing Technologies. Springfield: The Society for Imaging Science and Technology, 308-315.

\section{Autor/es}

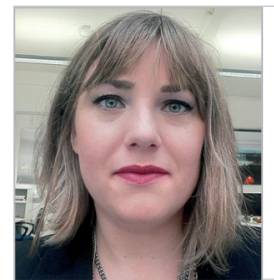

Iraia Anthonisen-Añabeitia
iraia.anthonisen@ehu.eus
Departamento de Pintura, Facultad de
Bellas Artes, Universidad del País Vasco
(UPV-EHU)

Licenciada en Bellas Artes (Conservación y Restauración de Bienes Culturales). Máster en Conservación y Exhibición de Arte Contemporáneo (CYXAC) por la Universidad del País Vasco (UPV/ EHU) (2013). Desde el 2015 imparte docencia en la Universidad del País Vasco (UPV-EHU) en el Grado de Conservación y Exhibición de Bienes Culturales. En la actualidad está finalizando su tesis doctoral internacional sobre el uso de las tecnologías de impresión digitales en la creación artística contemporánea y su conservación. Ha trabajado como conservadora-restauradora de obras contemporáneas y obra gráfica de carácter internacional pertenecientes a colecciones privadas, en las que también ha realizado trabajos de catalogación. Sus líneas de investigación se centran en la conservación y restauración de arte contemporáneo y obra gráfica, sistemas de impresión digital y documentación. https://orcid.org/0000-00024738-4027 